\title{
On the necessity and measures of cultivating students' ability of cross border in vocal music teaching in Colleges and Universities
}

\author{
Chunmei Rong ${ }^{1, \text { a }}$ \\ ${ }^{1}$ NINGXIA ART VOCATIONAL COLLEGE , NingXia, China,750021 \\ alj188@msn.com
}

\begin{abstract}
Keywords: colleges and universities; students; vocal music teaching; the ability of cross boundary; necessity; measures
\end{abstract}

Abstract. With the continuous development of the Performing Arts model, the cross border began to become the goal pursued in various forms of art. In the field of cross border music there are many forms of college students as future successor, it is necessary in college through reasonable and effective education mode, cultivate their ability to cross, so as to better adapt to the development of the times and art, become an all-round development of all-round talents. In this paper, the necessity and measures of cultivating students' cross - border ability in college vocal music teaching are considered.

\section{The meaning of cross border and the main form of vocal music}

Cross border, which means from the original boundaries of the cross, into a new range. With the continuous development of the cause of art, a lot of stars began to cross border performances, in recent years, the reality show continued hot, but also from the side reflects the degree of cross border behavior fiery. Cross vocal community, try many mainly from the singer's success, they are mastering their original singing at the same time, is also actively involved in different singing styles and techniques, and even out of singing, across the stage performances, film and TV industry [1]. From the current point of view, many people in the cross border, have achieved great success in the industry and the general recognition.

There are three types of crossover in choral music performance. The first is the singing style between the cross [2], here mainly refers to the singer to master two or more than two kinds of singing, and made use of singing skills according to different songs, and can reach a certain level. For example, the original learning bel canto singer to sing popular songs or folk songs, or pop singer to bel canto, and to achieve a certain concert standard, successful, and unanimously approved by the audience. Success in this cross-border form is known as "Chinese and Western Nightingale" of the famous singer Wu Bixia [3]. The "middle" in the excellent reputation refers to the Chinese national singing, while "the west" represents the bel canto in Western music. The most talked about is her concert, the first half is full of Western concert repertoire, the second half is our nation's repertoire, has proved that "the possibility of a multi-faceted" to everyone, but also bring you a visual feast, incomparable.

The second is the crossover. This type is mainly manifested in the singer singing style is no longer confined to the simple folk singing and bel canto, but by some methods such as starting, bearing, rotation, etc. These will discount "concert to a track fusion, thus forming a kind of singing method is different from the various, but the new canto from all kinds of singing. In this regard, make a success is a typical representative of our country's Li Guyi [4]. Li Guyi teachers through the national, popular and traditional opera three kinds of fusion, to create a new "people through" singing, and the majority of praise and praise. In addition, Zu Hai, Can Tang, who also carried out a bold innovation, the formation of a unique style of music in china.

The third kind of cross border singing form refers to the performance of the vocal music. Through the practice of all kinds of vocal skills, the singer will expand their range and tone, so as to be in a position to convert between various types of music and even different gender. The representative is Russian singer Vitas, he will be in a position to own range across five to eight degrees, it is a popular song or bel canto, can do handy. Vitas's treble part of pure and bright, the base area is full of solid, the level of its singing by the people from all over the world unanimously recognized, known as "dolphin sound" reputation [5]. In this regard, our country has a high degree of visibility is undoubtedly Li 
Yugang, the Spring Festival Gala on the stage of a new drunken concubine, greatly broadens people's horizons and appreciation level.

\section{The necessity of cultivating students' ability of cross-border in vocal music teaching}

2.1 Increasingly fierce social competition and severe employment situation

With the continuous development of China's education reform, college enrollment expansion has become a mainstream trend. College enrollment is the most direct effect of a lot of students dream of the University, but also to the employment of college students has brought great pressure. Nowadays, employment has become a social problem, choral music students are no exception. For college vocal music teaching, we should have a clear goal of schooling, then targeted training according to the actual situation of the students, help the students' all-round development, to enable them to graduate. Students of professional art colleges can get high quality training to after graduation is mainly engaged in special concert, ordinary college music teaching professional ability is relatively weak; compared with normal universities mainly in the basic education of music teachers, students of vocal music teaching in universities and a large gap with the. In this case, the students of vocal music majors in universities will choose more general, mass music work, it is also because of this, students' vocal college training objectives should tend to "Bo", and the "special" requirement, can reduce the relative number of [6]. In this case, it is extremely important to cultivate the ability of students to cross the border in vocal music teaching. It is of profound significance to improve the competitiveness of the students and to promote the employment of the students through the training of the students' abilities of various types.

2.2Current diversity and the characteristics of the times, the need to cultivate students' ability to cross the singing

In a very long time, in the China of popular music, are thousands of people out "and" people ", which is mainly due to the emergence of an idol, causes everybody to follow and imitate the. However, with the development of the times and people appreciate the level, this phenomenon began to produce fatigue, people are no longer satisfied with the performance of a single model, the fundamental reason is cross-border behavior, is the fruits of development of cultural diversity. People need to see and hear some new, different from the existing results of the singing, which is in line with the contemporary social development needs of the training objectives. Therefore, vocal music teaching should keep pace with the development of the times, keep pace with the times and the students"s ability to cross the border. After mastering some fixed singing in the students, provide the opportunity to let it continue to contact the new genre and singing style, and constantly stimulate students self learning interest, ability to maximize the potential to stimulate students, help them improve their own quality and singing, a good foundation for future employment. Cultivation of the comprehensive singing ability is also in accordance with the requirements of modern educational theory.

\section{Colleges and universities vocal music teaching in the cultivation of students ability to cross-border measures}

3.1 Basic Training of students' ability of cross boundary

In choral music teaching, we must first cultivate students' basic skills, including four elements, that is, breathing, phonation, resonance and language [7]. No matter what form of singing and style, cannot be separated from the four elements, but also on the basis of these four elements, to integrate, improve the overall quality of students. The following four elements will be discussed one by one.

First breath. Correct breathing is the foundation of all singing skills, and even in the bel canto there is still "singing is breathing". In the training of the students' daily breathing, the main method is the combination of chest and abdomen, which are the most widely accepted method of breathing training. The combination of abdominal and abdominal breathing method is able to fully regulate the human body breath, so that it is full and flexible, for the smooth, full and start to lay the foundation for singing. In practice, should adopt differences ideas, for example, in singing pop music, because of its widespread range is narrow, if the full use of the chest abdomen combined breathing method, is prone to sound and articulation is not flexible enough, lack of intimacy. Therefore, according to the 
requirements of different singing styles of skills, specific analysis of peculiar circumstances, so scientific and reasonable breathing.

Followed by the sound and resonance. No matter what kind of singing, pleasant sound is the premise of resonance, and the rational use of resonance, it is able to expand the volume, expand the range, while achieving a variety of styles. Performance in the training of cross-border ability, it is to establish a sense of learning from each other and learn from. For example, in Bel Canto often need to adopt mixed resonance technology, this is because the bel canto is about mixed sound effect, scientifically sound; national singing is to use more resonance and oral resonance, because it is the pursuit of bright sweet timbre; popular to sing the law is different, in order to sound cordial and natural, mainly by oral resonance and hypopharyngeal cavity resonance. Learn from each other in various forms between the performance of singing art songs, flexible reference articulation and sound national singing in flexibility in singing folk songs, from bel canto in science, to keep the sound filled and smooth etc..

Language and emotion. Emotion is the soul of singing, and language is an important carrier of emotional expression. For example, in the establishment of the singing techniques of singing, if you can make a complete vowel sound, you can beautify the voice, a more thorough expression of the feelings of the singer dripping. Again, national singing is the pursuit of flawless, complete with its own rules and singing techniques in articulation, sound with feeling and emotion. Therefore, in the process of cultivating students' ability to cross - border in vocal music teaching in colleges and universities, it is necessary to choose the singing techniques according to the actual needs of different songs. No matter what kind of form, the emotional expression should be placed in the first place, with a positive and optimistic attitude to experience the profound feelings contained in the works, which are the ultimate purpose of singing.

3 .2For different students' personality characteristics, targeted training

Whether it is the creation of the cause of modern vocal music, or all walks of life in the community, have clearly shown that the tradition of sticking to the drawbacks, showing the importance of bold innovation. This is the fundamental reason why we advocate the cultivation of students' ability to cross border in vocal music teaching in colleges and universities. The purpose of cultivating students' ability to cross boundary is to encourage the students to develop in a variety of ways, in order to adapt to the increasingly fierce social competition and employment pressure, to meet the needs of the current social development. How to encourage students to diversify, in the final analysis is tantamount to teach students in accordance with their aptitude. In fact, in vocal music teaching has long been the existence of cross talk, but has not yet grown to the height of the theory. China's famous scientist Jin Tielin once in the vocal music teaching work put forward "to the same difference, with" teaching idea, pay attention to the different singing techniques for organic integration, and according to the characteristics of different students, to maximize their singing potential, and develop targeted personalized training plan. Under this kind of teaching idea, has cultivated Song Zuying. Wu Bixia, and so on the national and the bel canto excellent singer, has obtained many previous successful experiences.

And specific to the vocal music teaching in colleges and universities, is to proceed from the actual situation of vocal music students, understand their interests, and can stimulate the students' learning initiative program, for them to choose the most reasonable form of cross-border. For example, in the process of learning, some students are interested in pop music, and put more time into the study of pop music. So, even if it is difficult to really pop music into the teaching of traditional music, but also to encourage them to carry out systematic training, so as to move closer to the popular music to achieve the dream of singing.

3.3Enrich and improve the vocal music teacher's personal accomplishment

Nowadays, with the increasing application of cross-border in vocal music teaching, teachers are also more stringent requirements. This is because under the pressure of increasingly fierce social competition. The problem of student employment is largely dependent on the ability of teachers. If the university teachers have a strong sense of responsibility, able to recognize all kinds of cross border enhancement effect on students, and actively update their teaching mode, the adjustment of 
traditional teaching methods, the students will also be bound to a new range of skills, demonstrated the unique superiority in the social competition. Secondly, choral music teachers should set up the idea of continuous learning and lifelong learning. The continuous development of vocal art changes, in this case if teachers complacent, do not renew their knowledge structure, is bound to be eliminated from the society. In the end, it is a need for a good relationship between teachers and students. This is because the vocal music teaching is different from other professional college, there are many separate contact between teachers and students of the opportunity, if you want to successfully carry out the work of teaching between teachers and students, the harmonious relationship between teachers and students is very important, otherwise it is difficult to achieve the ideal teaching effect.

All in all, there are more and more cross border phenomena in the society, which is the inevitable result of the development of cultural pluralism. This is in line with the trend of social development, is the future direction of the development of various industries. As a vocal music teaching, should also keep pace with the times, in the work of teaching will cultivate students' ability to cross border as one of the teaching goals, the balanced development of all aspects of security of the students, make our students, not only has the scientific singing method, also has a distinct personality style, while China's vocal music and cultural development, will also benefit promote the development of.

\section{References:}

[1]Yamada T. The use of cross-border counter-force against hostile armed bands and the doctrine of necessity : a study of the Turkish incursions into northern Iraq[J]. Developmental Biology, 2011, 356(1):9484-9.

[2]Joseph A C, Joseph S E, Chen G. Cross-border portfolio investment networks and indicators for financial crises[J]. Scientific Reports, 2013, 4(2):3991.

[3]Picard N, Strick P L. Motor areas of the medial wall: a review of their location and functional activation[J]. Cerebral Cortex, 1996, 6(3):342-353.

[4]Doł zbł asz S. Symmetry or asymmetry? Cross-border openness of service providers in Polish-Czech and Polish-German border towns[J]. Moravian Geographical Reports, 2015, 23(1):2 - 12.

[5]Payne J. Cross-border Schemes of Arrangement and Forum Shopping[J]. European Business Organization Law Review, 2013, 14(4):563-589.

[6]Calvert G A, Campbell R. Reading Speech from Still and Moving Faces: The Neural Substrates of Visible Speech[J]. Journal of Cognitive Neuroscience, 2003, 15(1):57-70.

[7]Bollinger B, Gillingham K. Peer Effects in the Diffusion of Solar Photovoltaic Panels[J]. Marketing Science, 2012, 31(6):900-912. 